\title{
Implementation of a Community- based Project on the Prevention of Cardiovascular Diseases through Risk Factor Reduction in Phase $1 K$-Kasiglahan Village, Barangay San Jose, Rodriguez, Rizal, Philippines
}

\author{
Clarenz Sarit M. Concepcion, RMT, MPHIa,b,c, \\ Wilhelmina A. Mercado, $M D^{a, c}$
}

\begin{abstract}
This capstone project of the Master in Public Health International of the Faculty of Medicine and Surgery initiated the development of community health programs. Phase 1K, Kasiglahan Village, Barangay San Jose, Rodriguez, Rizal, a partner community of the University of Santo Tomas - SIMBAHAYAN Community Development Office was chosen as the primary stakeholder for the implementation of this capstone project.
\end{abstract}

Addressing the identified priority problem of lacking a community-based strategy in the community, the project aimed to initiate community-based prevention of cardiovascular diseases (CVDs) through risk factor reduction in Phase 1K-Kasiglahan Village, Barangay San Jose, Rodriguez, Rizal at the end of the 6-week project timeline. Specifically, the project aimed (1) to increase the mobilization of the community through a consultative workshop, (2) to raise awareness of

Clarenz Sarit M. Concepcion

cmconcepcion@ust.edu.ph

a. Master in Public Health (International), Faculty of Medicine and Surgery, University of Santo Tomas

b. Department of Medical Technology, Faculty of Pharmacy, University of Santo Tomas

c. Faculty of Medicine and Surgery, University of Santo Tomas the community through Information, education, and communication (IEC) materials, and (3) to increase the baseline knowledge of the community through public health education lay forum.

The project outputs include (1) mobilization of the community leaders in identifying their own health problems and in formulating their interventions, (2) posting and distribution of IECs in the community, and (3) increased baseline knowledge after the public health education lay forum.

With the potential of influencing local policies to improve the health of the community, this project was formally and officially endorsed to the community through its local government leaders, rural health unit officials, and community leaders.

Key words: community-based project, public health education, health promotion, cardiovascular diseases, risk factor

\section{INTRODUCTION}

The immensity of current public health problems has significantly impacted the community; and as such requires the best attention that public health has to offer. Settling on the curative aspect of health alone would not suffice. Community-level solutions to protect 
health and prevent diseases must be implemented. Through this capstone project, the Master in Public Health International of the Faculty of Medicine and Surgery, in partnership with the University of Santo Tomas - SIMBAHAYAN Community Development Office, initiates the development of community health programs that ensure community engagement and ownership.

Phase 1K, Kasiglahan Village, Barangay San Jose, Rodriguez, Rizal, a partner community of the University of Santo Tomas, was chosen as the primary stakeholder for the implementation of this capstone project.

When identifying the health problem in Phase 1K, Kasiglahan Village, data was gathered through (1) ocular inspection, (2) focus group discussion, (3) interview, and (4) collection of secondary data or review of records.

An ocular inspection was conducted around the fifteen (15) blocks of Phase 1K, Kasiglahan, to assess the community situation. This was followed by a focus group discussion with the community leaders where common health issues and problems were presented. Further data gathering through a review of records or secondary data was then done to validate and verify the health issues previously identified.

Noncommunicable diseases, specifically CVDs, were found to be the leading disease burden in the community. Based on the mortality report collected from the rural health unit (RHU) of Rodriguez, Rizal, noncommunicable diseases (NCDs) dominated the leading causes of mortality in the municipality (see Table 1).[1]

NCDs, however, is observed to be overshadowed by infectious diseases as a priority in the community even though these diseases accounted more than double the number of deaths from all infectious diseases, maternal and perinatal conditions, and nutritional deficiencies combined.

Therefore, a balance must be struck as NCDs, especially CVDs, can no longer be ignored. The community should not only deal with their current burden of infectious diseases, but also with the growing burden of chronic diseases.

CVDs together with the major NCDs such as diabetes, cancer, and chronic respiratory diseases share four common modifiable behavioral risk factors, namely: unhealthy diet, smoking tobacco, physical inactivity, and excessive use of alcohol.[2]
Table 1. Top 10 Leading Causes of Mortality, 2017, Rodriguez, Rizal

\begin{tabular}{lcc}
\hline \multicolumn{1}{c}{ Cause of Death } & $\begin{array}{c}\text { Number of } \\
\text { Cases }\end{array}$ & Percentage \\
\hline $\begin{array}{l}\text { Acute Myocardial } \\
\text { Infarction }\end{array}$ & 402 & $44.77 \%$ \\
$\begin{array}{l}\text { Medico Legal Cases } \\
\text { (Gunshot Wound) }\end{array}$ & 85 & $9.47 \%$ \\
Community Acquired & 74 & $8.24 \%$ \\
Pneumonia & 74 & $8.24 \%$ \\
Acute Respiratory Failure & 64 & $7.12 \%$ \\
Cardiac Arrhythmia & 51 & $5.68 \%$ \\
Septicemia & 40 & $4.45 \%$ \\
Hypertension & 37 & $4.12 \%$ \\
Pulmonary Tuberculosis & 36 & $4.00 \%$ \\
Cerebrovascular Accident & 35 & $3.90 \%$ \\
Cardiogenic Shock & 898 & $100 \%$ \\
Total & & \\
\hline
\end{tabular}

Source: Mortality Report Rural Health Unit, Rodriquez, Rizal, 2018

Interventions to reduce these four main modifiable risks related to lifestyle or behavior are the key elements for effective primary prevention and control of NCDs.[3]

An interview with the NCD coordinator of Rodriguez, Rizal aided in examining the status of NCD-CVD preventive programs of the Rural Health Unit (RHU) and the local government. Based on the interview, preventive programs were available such as risk factor assessment, screening tests, and healthy lifestyle education. The problem, however, was the inability of these preventive programs to reach the communities. Programs initiated from the health center and local government down to the community provided little opportunity for people's participation and ownership leading to this initiative being unsuccessful.

Addressing the identified priority problem of lacking a community-based prevention program, this capstone project aimed to initiate communitybased prevention of CVDs through risk factor reduction in Phase 1K-Kasiglahan Village, Barangay San Jose, Rodriguez, Rizal at the end of the 6-week project timeline. Specifically, the project aimed at (1) increasing the mobilization of the community, (2) raising awareness of the community, and (3) increasing the baseline knowledge of the community on prevention of CVDs and risk factor reduction. 
Implementation of this project makes Phase 1K-Kasiglahan Village, Barangay San Jose, Rodriguez, Rizal a model for community-based prevention of CVDs with health promotion as its approach, and social marketing and social mobilization as its delivery strategy. This project has the potential of influencing local (barangay and provincial) and national policies that shape health. Furthermore, this initiative has multiplicative health, social and economic advantages that will contribute to achieving sustainable development goal (SDG) 3 (good health and well-being), SDG 17 (partnerships) as well as other goals including SDG 8 (economic growth) and SDG 10 (reduced inequalities).[4] It is also a key driver to the Philippine Development Plan 2040 by fostering community development and social integration.[5]

\section{METHODOLOGY}

The project followed a 6-week timeline from November to December 2019. Weeks one (1) and two (2) were allotted for the program preparation. Preparation involved performing situational analysis and health needs assessment. After assessing the community's health needs, project planning to identify the appropriate interventions and logistics preparation were performed. Subsequently, week three (3) to week five (5) were designated for the implementation of the project components. Week 6 was scheduled for a disengagement activity where the project was formally endorsed to the community for sustainability.

Three (3) components were laid out based on specific objectives of the project. Table 2 outlines the project components, the timeline for each component, and the specific objective it addresses.

The project was mainly participated by the community members, community leaders, Barangay officials, and members of the rural health unit (RHU) of San Jose, Rodriguez, Rizal. In each of the project components, the participants were asked to sign an attendance sheet and a consent form stating their agreement to disclose their information, pictures, and outputs for project publication.

\section{Component 1: Consultative Workshop}

Forty-five (45) cluster leaders, three (3) from each of the fifteen (15) blocks, together with the RHU members and officials of Barangay San Jose were invited to attend the workshop. The participants were divided into six (6) groups for easier supervision. The groups were tasked with identifying issues and barriers in their community contributing to the increasing cases of CVDs. They were instructed to create a problem tree using the "But Why" method. Subsequently, the groups were asked to provide solutions on each identified problem, translating it into an intervention tree. They were given one hour to accomplish the task. Each group then presented their outputs to their fellow members for community dialogue. After the workshop, the facilitators synthesized the activity outputs.

\section{Component 2: Information, Education, and Communication (IEC) Materials Development and Distribution}

The Global Action Plan for the Prevention and Control of NCDs 2013 - 2020 by the World Health

Table 2. Project Components of the Community-based Project on the Prevention of Cardiovascular Diseases through Risk Factor Reduction in Phase 1K-Kasiglahan Village, Barangay San Jose, Rodriquez, Rizal, 2019

\section{Project Components}

1. Consultative Workshop

\section{Project Timeline}

Week 3

November 19 to 23, 2019

2. Information, Education, and Communication (IEC) Materials Development and Distribution

3. Public Health Education Lay Forum
Week 4

November 26 to 30,2019

Week 5

December 3 to 7,2019

\section{Specific Objectives to be Addressed}

1. To increase mobilization of the community on the prevention of cardiovascular diseases and risk factor reduction through a consultative workshop by the end of week 3.

2. To raise awareness of the community on the prevention of cardiovascular diseases and risk factor reduction through Information, Education, and Communication (IEC) materials by the end of week 4 .

3. To increase baseline knowledge of the community on the prevention of cardiovascular diseases and risk factor reduction through Public Health Education Lay Forum by end of week 5 . 
Organization [6] and the Department of Health's National Policy on Strengthening the Prevention and Control of Chronic Lifestyle Related NonCommunicable Diseases [7] served as the reference in composing the content of the IEC materials. Correspondingly, the IECs were made specific to the community health needs through the identified problems and proposed interventions during the consultative workshop.

A series of consultation meetings with the community leaders, RHU members, and Barangay officers were also performed to design and produce the IECs. This ensured that the materials were clear, relevant, communicated specific messages, and easily remembered by the community members.

The channels of IEC materials used in this project were printed media, specifically, posters, flyers, and notepads. The community leaders then posted and distributed the IECs during the public health education lay forum. Additionally, these were also distributed and posted in the health centers and health stations.

\section{Component 3: Public Health Education Lay Forum}

Fifty-eight (58) participants from the different blocks of Phase 1-K, Kasiglahan Village, attended the organized lay forum on CVD prevention. Four (4) lectures were conducted, namely: (1) Physical Activity, (2) Healthy Diet, (3) Smoking Cessation, and (4) NCD screening and diagnostic tests. The lectures were primarily focused on increasing the community's knowledge on CVDs and its major modifiable lifestyle-related risk factors. Experts in their respective fields were invited to share their knowledge in targeting the NCDs/CVDs modifiable risk factors. Other than the lectures, activities were set to engage the community participants and emphasize on what has been learned. These included games, health food serving, and an exercise activity named "Gumalaw at Humataw".

A ten (10) point pre-test and post-test were given in every lecture to measure the increase in the participant's baseline knowledge. The results of the pre-test and post-test scores were analyzed using Statistical Package for the Social Sciences (SPSS) version 25.0. Paired t-test was used to determine the significant difference in the test scores.

\section{RESULTS}

\section{Consultative Workshop}

The consultative workshop mobilized the community leaders in identifying their own health problems and formulating interventions. Figure 1 shows the synthesized interventions presented during the workshop, translated from the identified problems. The highlighted portion depicts the prioritized interventions in the project given there was only limited time and resources. Discussing the identified problems and proposed interventions were done through a community dialogue as evidenced in Figure 2.

\section{IEC Materials Development and Distribution}

The poster and flyer design bearing messages for CVD prevention through risk factor reduction were shown in Figure 3. It was written in Filipino for community members to understand easily. The material underscored the burden of CVDs, the common symptoms and need to seek immediate healthcare once experienced, the four common lifestyle-related modifiable risk factors, and the ways to prevent CVDs by promoting a healthy lifestyle. Figure 4 shows the posting and distribution of IECs in the community during the Public Health Lay Forum.

\section{Public Health Education Lay Forum}

Table 3 shows the increased baseline knowledge after the public health education lay forum with a series of lectures on physical activity, healthy diet, smoking cessation, and health services for the prevention of CVDs. As presented, it was evident that after the public health educational lecture, the participant's mean test score significantly improved $(p<0.001)$. At an average, their test score on physical activity increased by 1.94 points (1.61 to 2.27), on healthy diet increased by 3.12 points (2.70 to 3.54$)$, on smoking cessation increased by 2.73 points (2.18 to 3.28$)$, and on health services for prevention and control of CVDs increased by 2.91 points ( 2.40 to 3.43 ).

Community members also participated in the lecture activities. Figure 5 shows the participating members in the exercise activity called "Gumalaw at Humataw". Other activities include serving a healthy and balanced meal, and games like "Pinoy Henyo" and "Fact or Bluff". 


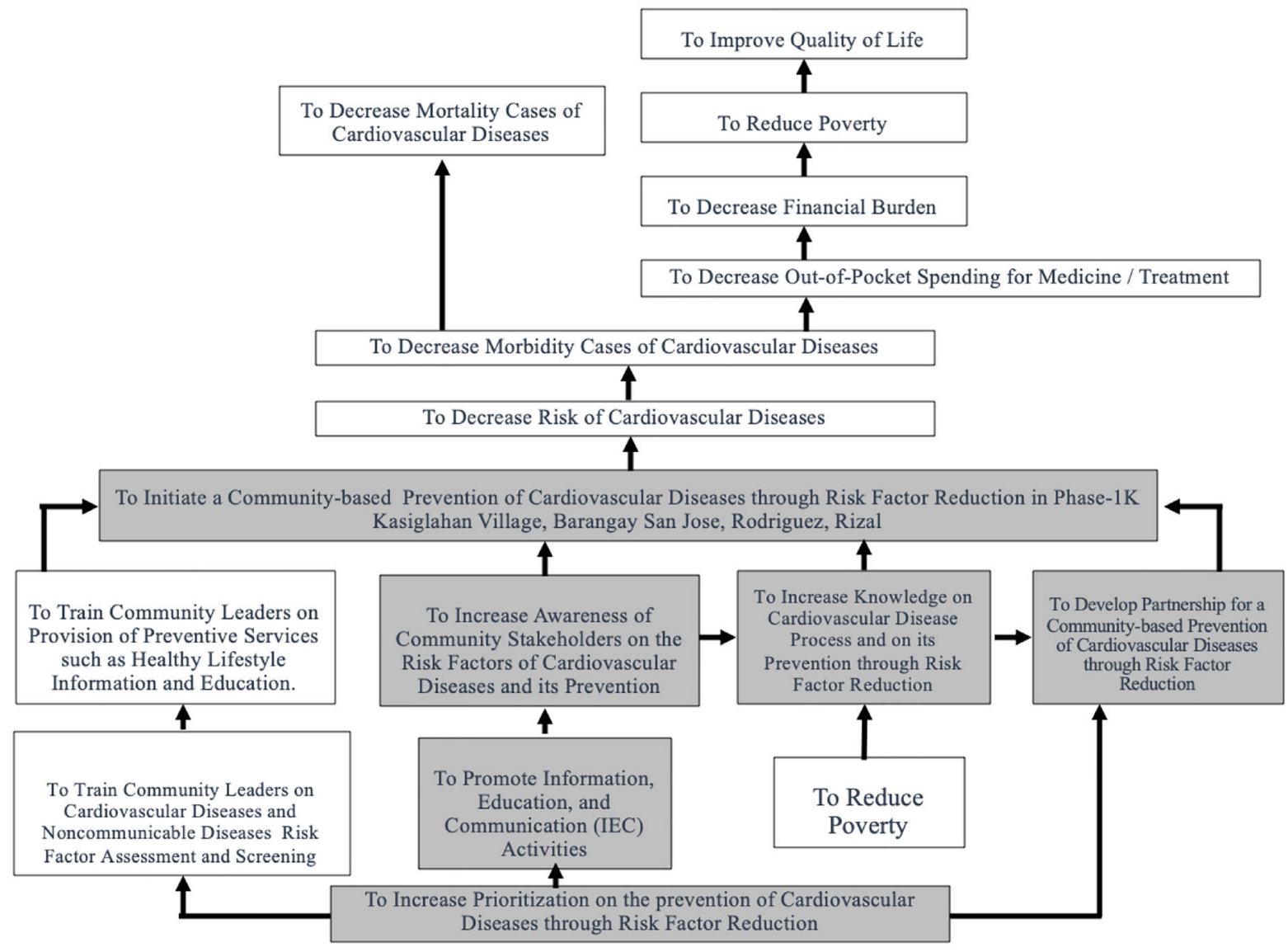

Figure 1: Intervention tree formulated by the community leaders using the "But Why" method during the consultative workshop in Phase 1K, Kasiglahan Village, Barangay San Jose, Rodriguez Rizal, November 2019.

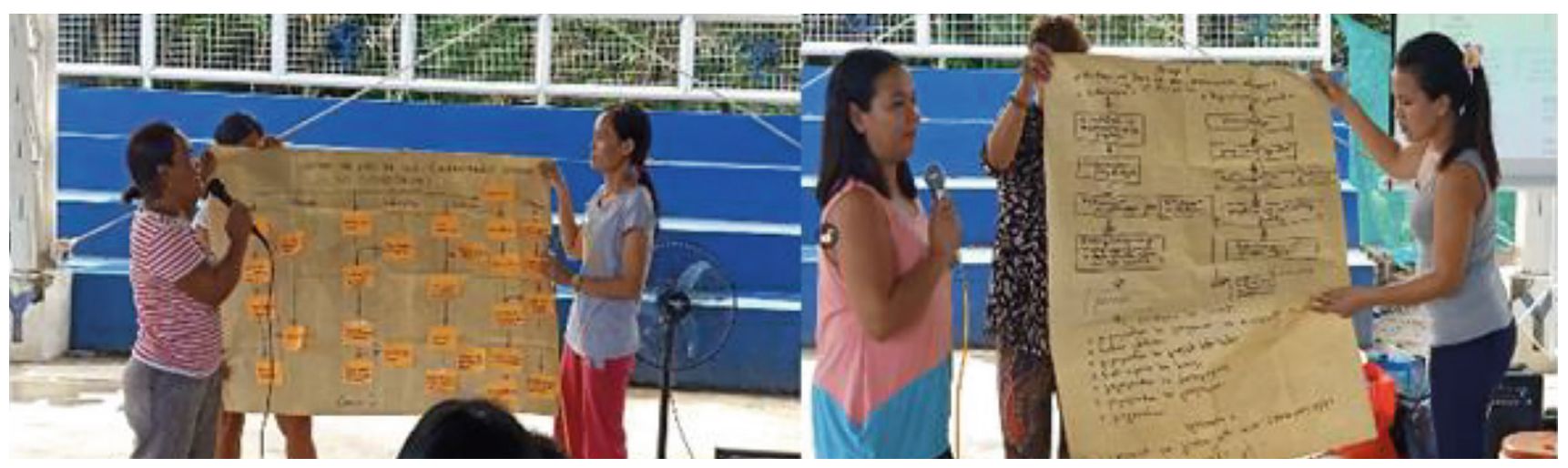

Figure 2: Community dialogue during the consultative workshop in Phase 1K, Kasiglahan Village, Barangay San Jose, Rodriguez Rizal, November 2019.

\section{DISCUSSION}

\section{Consultative Workshop}

The consultative workshop in this project ensured the community members' participation and mobilization in identifying, prioritizing, and responding to their own health needs. As outlined in the Ottawa Charter, health promotion initiatives should be participatory and empowering. Community members must be involved in all stages of planning and implementation to address their own health needs and gain greater control over their health and its determinants.[8] For a community-based prevention intervention to be successful, according to Daoud and Meddeb (2019), it must involve collaboration and community participation to highlight empowerment and emphasize context.[9]

North Karelia project is the most frequently cited example of a community-based project for CVD 


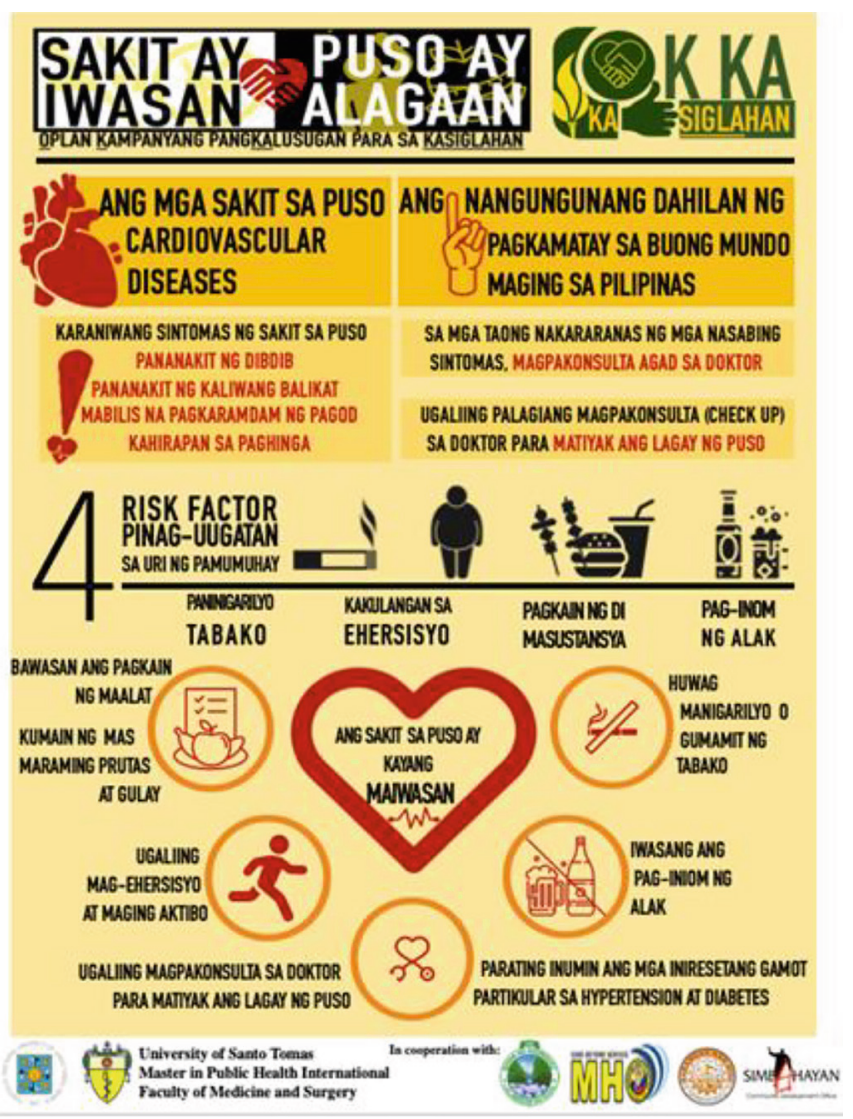

Figure 3: Poster and flyer design for cardiovascular disease prevention in Phase 1K, Kasiglahan Village, Barangay San Jose, Rodriguez Rizal, November 2019.

prevention. Achievements of the project include reducing cardiovascular mortality by $80 \%$, reducing smoking rates from $52 \%$ to $31 \%$, and reducing all cancers by $71 \%$.[10] Serving as a model for the Phase 1K Kasiglahan project, the North Karelia project was similarly formulated and implemented through the mobilization and action of the people themselves.

\section{IEC Materials Development and Distribution}

Using IEC materials, social marketing and mobilization were the strategies used in this project to increase awareness in the community on the prevention of CVDs and risk factor reduction. According to the study of Khan, et al. (2005), these strategies increase the awareness and participation of the community in preventing and controlling diseases.[11]

Daoud and Meddeb (2019) emphasized the use of social marketing as a delivery strategy in public health education in order to reach a broader segment of the population as well as to influence action and change behavior towards social benefit.[9]

IEC materials in this project were used as powerful tools to increase the reach of health education and promotion services in the community by disseminating clear messages and awareness on the prevention of CVDs through risk factor reduction. It was intended to instill positive awareness for appropriate lifestyle behavior modifications amongst the community.

\section{Public Health Education Lay Forum}

As defined by the World Health Organization (WHO), health education is any combination of learning experiences designed to help individuals and communities improve their health by increasing their knowledge and influencing their behavior.[12]

Public health education, according to the Institute of Medicine (IOM), are strategies that seek to increase people's knowledge about

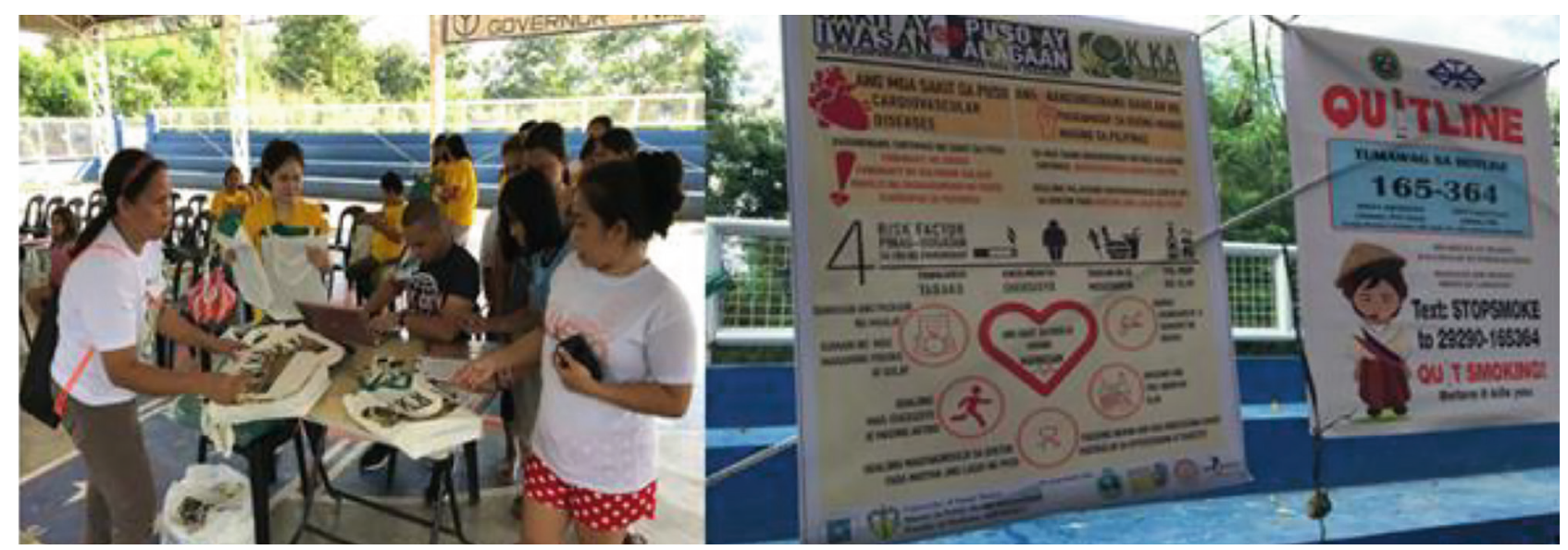

Figure 4: Posting and distribution of information, education, and communication materials prevention in Phase 1K, Kasiglahan Village, Barangay San Jose, Rodriguez Rizal, November 2019. 
Table 3. Effect of Public Health Educational Lectures on the Knowledge of Community Members Measured using Pre- and Posttests in Phase 1K, Kasiglahan Village, Barangay San Jose, Rodriquez Rizal, December 2019.

\begin{tabular}{|c|c|c|c|c|c|c|}
\hline & \multicolumn{2}{|c|}{ Pre-test } & \multicolumn{2}{|c|}{ Post-test } & \multirow[t]{2}{*}{$p$ value } & \multirow{2}{*}{$\begin{array}{l}\text { Difference in Means } \\
\qquad(95 \% \mathrm{Cl})\end{array}$} \\
\hline & $\begin{array}{l}\text { Number of } \\
\text { Participants }\end{array}$ & $\begin{array}{l}\text { Mean } \\
\text { Score }\end{array}$ & $\begin{array}{l}\text { Number of } \\
\text { Participants }\end{array}$ & $\begin{array}{l}\text { Mean } \\
\text { Score }\end{array}$ & & \\
\hline $\begin{array}{l}\text { Lecture 1: } \\
\text { Physical Activity }\end{array}$ & 50 & 6.44 & 50 & 8.38 & $p<0.001$ & $\begin{array}{l}1.94 \\
(1.61 \text { to } 2.27)\end{array}$ \\
\hline $\begin{array}{l}\text { Lecture 2: } \\
\text { Healthy Diet }\end{array}$ & 33 & 3.36 & 33 & 6.48 & $p<0.001$ & $\begin{array}{l}3.12 \\
(2.70 \text { to } 3.54)\end{array}$ \\
\hline $\begin{array}{l}\text { Lecture 3: } \\
\text { Smoking } \\
\text { Cessation }\end{array}$ & 37 & 5.95 & 37 & 8.68 & $p<0.001$ & $\begin{array}{l}2.73 \\
(2.18 \text { to } 3.28)\end{array}$ \\
\hline $\begin{array}{l}\text { Lecture 4: } \\
\text { Health Services }\end{array}$ & 35 & 3.83 & 35 & 6.74 & $p<0.001$ & $\begin{array}{l}2.91 \\
(2.40 \text { to } 3.43)\end{array}$ \\
\hline
\end{tabular}

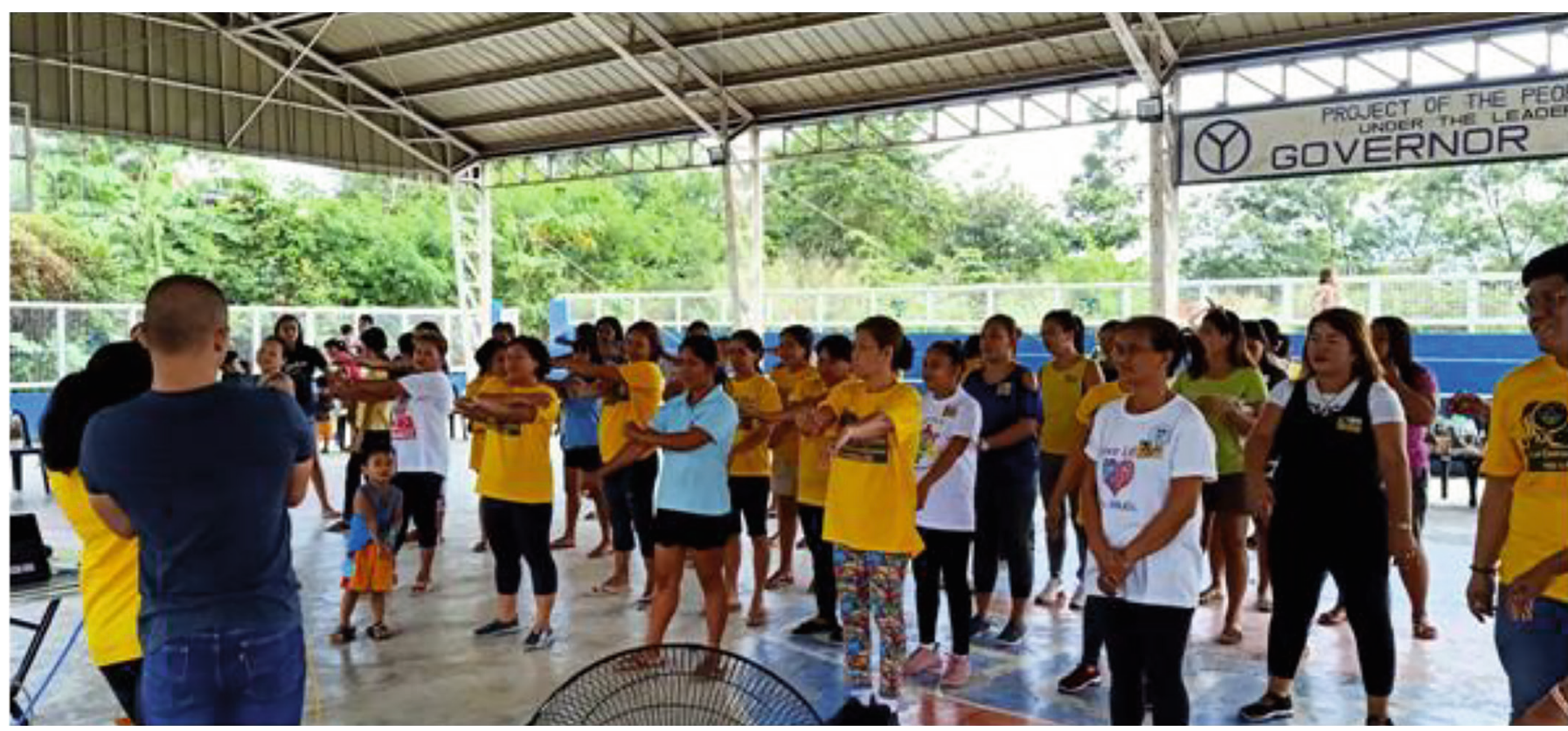

Figure 5: Exercise activity "Gumalaw at Humataw" in Phase 1K, Kasiglahan Village, Barangay San Jose, Rodriguez Rizal, December 2019.

health, risk factors, determinants, and lifestyle. It is based on the premise that recognizing what is good for oneself is vital for behavior change.[13] Hence, seeking to increase people's awareness, knowledge about chronic disease risk factors and lifestyle are essential prevention interventions for CVDs and other non-communicable diseases.

\section{CONCLUSION}

This project, with its three components, namely (1) Consultative Workshop, (2) IEC materials development and distribution, and (3) Public Health Education Lay Forum, made Phase 1K-Kasiglahan Village, Barangay San Jose, Rodriguez, Rizal a model for community-based prevention of CVDs with health promotion as its approach, and social marketing and social mobilization as its delivery strategy. With the potential of influencing local policies to improve community health, this project was formally and officially endorsed to the community through its local government leaders, rural health unit officials, and community leaders. 


\section{REFERENCES}

1. Rural Health Unit. Mortality report. Rodriguez, Rizal; 2018 (Unpublished).

2. World Health Organization. Tackling NCDs 'Best buys' and other recommended interventions for the prevention and control of noncommunicable diseases [Internet]. c2017 [cited 2019 November 8]. Available from: https://apps. who.int/iris/bitstream/handle/10665/259232/WHONMH-NVI17.9eng.pdf; jsessionid=CBC47C 11 D5 137333 D180101ADA29ECE3? sequence $=1$

3. Jeet G, Thakur JS, Prinja S, Singh M, Paika R, Kunjan K, et al. Effectiveness of targeting the health promotion settings for non-communicable disease control in low/middleincome countries: systematic review protocol. BM Open [Internet]. 2018 Jun;8(6):e014559. Available from: http:// dx.doi.org/10.1136/bmjopen-2016-014559

4. United Nations Development Agency. Sustainable development goals [Internet]. c2019 [cited 2019 December 30]. Available from: https://www.undp.org/content/undp/en/ home/sustainable-development-goals.html

5. National Economic and Development Authority. Philippine development plan 2017-2022 [Internet]. c2017 [cited 2019 December 18]. Available from: http://www. neda.gov.ph/wp-content/uploads/2017/12/AbridgedPDP-2017 2022_Final.pdf

6. World Health Organization. Global action plan for the prevention and control of noncommunicable diseases 2013-2020 [Internet]. c2013 [cited 2019 December 30]. Available from: https://apps.who.int/iris/bitstream/ handle/10665/94384/9789241506236_eng. pdf? sequence $=1$

7. Department of Health - Philippines. National policy on strengthening the prevention and control of chronic lifestyle related non-communicable diseases [Internet]. c2018 [cited 2019 December 14]. Available from: https://www.doh. gov.ph/lifestyle-related-diseases

8. World Health Organization. The Ottawa charter for health promotion [Internet]. c2019 [cited 2019 December 30]. Available from: https://www.who.int/healthpromotion/ conferences/previous/ottawa/en/

9. Daoud IM, Meddeb M. The Role of Social Marketing in Preventing the Spread of Non-Communicable Diseases. In: Advances in Electronic Government, Digital Divide, and Regional Development [Internet]. IGI Global; 2019. p.76-95.
Available from: http://dx.doi.org/10.4018/978-1-52255984-9.ch004

10. World Health Organization. Successful prevention of noncommunicable diseases: 25 years experiences with North Karelia Project in Finland [Internet]. c2002 [cited 2020 January 4]. Available from: https://www.who.int/chp/ media/en/north_karelia_successful_ncd_prevention.pdf

11. Khan NC, Thanh HTK, Berger J, Hoa PT, Quang ND, Smitasiri $S$, et al. Community Mobilization and Social Marketing to Promote Weekly Iron-Folic Acid Supplementation: A New Approach Toward Controlling Anemia Among Women of Reproductive Age in Vietnam. Nutrition Reviews [Internet]. 2008 Jun 28;63:S87-94. Available from: http://dx.doi. org/10.1111/i.1753-4887.2005.tb00166.x

12. World Health Organization. Health education [Internet]. c2019 [cited 2019 December 19]. Available from: https:// www.who.int/topics/health_education/en/

13. Institute of Medicine. An integrated framework for assessing the value of community-based prevention [Internet]. c2012 [cited 2019 December 29]. Available from: https://www. ncbi.nlm.nih.gov/books/NBK206926/pdf/Bookshelf_ NBK206926.pdf

(c) (i) (2) Open Access This article is licensed under a (creative Commons Attribution-NonCommercialShareAlike 4.0 International License, which permits use, share - copy and redistribute the material in any medium or format, adapt - remix, transform, and build upon the material, as long as you give appropriate credit, provide a link to the license, and indicate if changes were made. You may do so in any reasonable manner, but not in any way that suggests the licensor endorses you or your use. You may not use the material for commercial purposes. If you remix, transform, or build upon the material, you must distribute your contributions under the same license as the original. You may not apply legal terms or technological measures that legally restrict others from doing anything the license permits. The images or other third party material in this article are included in the article's Creative Commons license, unless indicated otherwise in a credit line to the material. If material is not included in the article's Creative Commons license and your intended use is not permitted by statutory regulation or exceeds the permitted use, you will need to obtain permission directly from the copyright holder. To view a copy of this license, visit https://creativecommons.org/licenses/by-nc-sa/4.0/. 